\title{
GEOTHERMAL INJECTION MONITORING PROJECT
}

L. Younker

with contributions from:

P. Kasameyer

A. Smith

E. Didwall

J. Hanson

D. $\mathrm{He} 1 \mathrm{~m}$

JCID- -19066

W. Murray

J. Hearst

Apri1, 1981

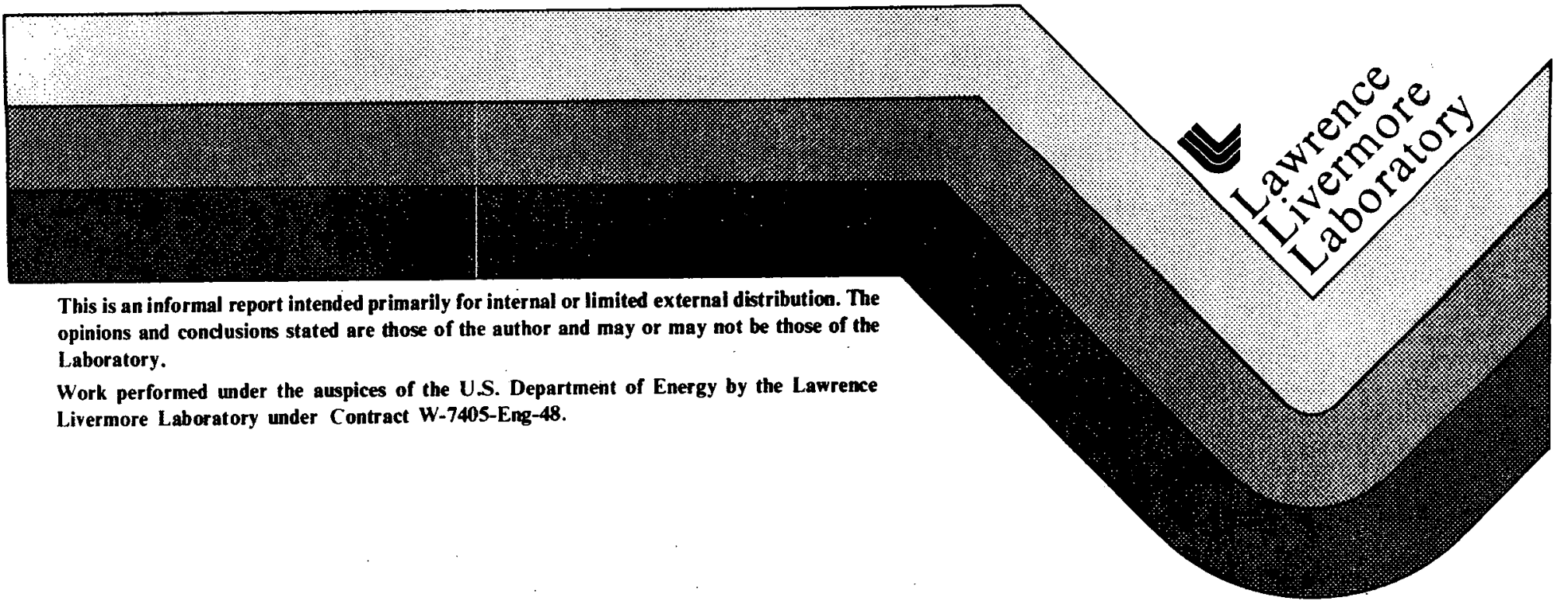




\section{DISCLAIMER}

This report was prepared as an account of work sponsored by an agency of the United States Government. Neither the United States Government nor any agency Thereof, nor any of their employees, makes any warranty, express or implied, or assumes any legal liability or responsibility for the accuracy, completeness, or usefulness of any information, apparatus, product, or process disclosed, or represents that its use would not infringe privately owned rights. Reference herein to any specific commercial product, process, or service by trade name, trademark, manufacturer, or otherwise does not necessarily constitute or imply its endorsement, recommendation, or favoring by the United States Government or any agency thereof. The views and opinions of authors expressed herein do not necessarily state or reflect those of the United States Government or any agency thereof. 


\section{DISCLAIMER}

Portions of this document may be illegible in electronic image products. Images are produced from the best available original document. 
BRINE INJECTION - REVIEW

Characteristics of Geothermal Brines

Disposal Methods

Injection Strategies

Monitoring Strategies

Geothermal Injection - Summary

MONITORING APPROACHES - EVALUATION

Regions Surrounding an Injection Well

Flow front

Thermal front

Pressure regime

Porosity and Permeability Changes

Hydrofracturing and Fluid Turbulence

Idealized Injection Well

Factors Controlling Types of Anomalies Present at a Given Site

Alternative Injection Programs

Reservoir Characteristics

Remote Monitoring Approaches

BRINE INJECTION MONITORING PROJECT - OVERVIEW

SUMMARY

REFERENCES

APPENDIX A - BRINE INJECTION MONITORING APPROACHES

APPENDIX B - LLNL PARTICIPANTS AND OUTSIDE CONTACTS

APPENDIX C - SCHEDULE AND MILESTONES

49
15

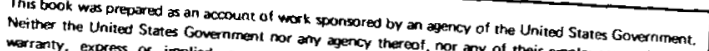

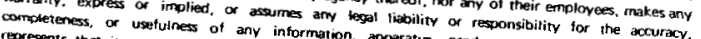

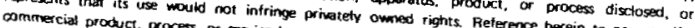

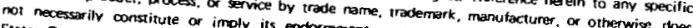

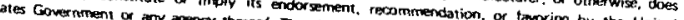
necessarily state or reflest thoshy 


\section{Abstract}

The development: of an economic and reliable system to track the movement of injected geothermal fluid would facilitate the rapid production of energy from hot water geothermal systems. A remote detection system could complement the existing methods and be incorporated into a total brine management program which includes witness well techniques and reservoir modeling.

The injection of spent fluid into a geothermal reservoir can potentially produce detectable geophysical anomalies. The injected fluid will have temperature and perhaps chemical differences when compared to the in-situ formation fluid. These differences may lead to differences in density, electrical properties, and acoustic transmission characteristics which can be detected and related to the position of the injected fluid. In addition, pressurization of the reservoir and the resulting development of fractures may produce microseismic events capable of being detected above background noise. Ground motion related to the injection process may also be present. A variety of factors unique to each geothermal site will control the detectability of these processes and their relationship to the position of the injected fluid.

The LLNL geothermal injection project will involve three major tasks in FY81. The first task and major objective of the program is to evaluate the range of approaches available to monitor the movement of injected fluid. The second task is concerned with preparation for an eventual field experiment. If some monitoring approaches are deemed feasible, then a field experiment to rigorously test a complete monitoring system would be necessary. A third task which reviews groundwater regulations and injection programs will be completed in order to insure that the results of the project are directed toward the 
needs of geothermal operators and developers. This task will assess whether additional monitoring approaches are necessary or desirable. Assuming that the initial assessment identifies effective monitoring techniques, we will prepare an experimental design for a field experiment which will (1) rigorously test the possibility of using remote observations to monitor fluid movement and (2) determine the extent to which such monitoring can reduce the need for witness wells. 


\section{INTRODUCTION}

The development of high-temperature, liquid-dominated geothermal resources for the generation of electricity will require the production and ultimate disposal of large volumes of fluid. The presence of salts, relatively high rejection temperatures from the energy conversion system, and the discharge volumes all dictate that subsurface injection of the wastewater is often the only environmentally acceptable scheme for disposal. The practical feasibility of the required long-term, large-volume reinjection of geothermal fluid has yet to be established.

Critical areas of concern are (1) the long-term injectability of the fluid and (2) the movement and effects of the fluids as they enter the subsurface formation. The Eirst area basically deals with the question of whether the used geothermal fluids (often corrosive, high-salinity brines) can be routinely handled at the surface and reinjected without major problems and delays, and has been the subject of extensive government and industrial funded research. Owen and Quong (1979) have recently reviewed the technology available to improve the long-term injection performance of brine wells. The second question deals with whether a long-term injection program can be implemented without serious pollution of groundwater resources. It also deals with whether a given injection program is compatible with, and supportive of, the long-term resource development program.

Our project deals with the second area of concern. In order to insure that the objectives of an injection program are realized without undue risk of 
environmental deterioration, a method to monitor the movement of the injected fluid is necessary. The ultimate goal of the LLNL brine injection monitoring project is to evaluate a range of approaches available to achieve this goal. Initially, the evaluation will be concerned with the scientific reliability of a given approach. Later analysis will address the question of economics and efficiency.

Activities for the first year of the program can be grouped into three general areas:

- Assess the impact of existing ground water regulations on geothermal injection programs.

- Evaluate the range of approaches potentially available to monitor brine movement and meet groundwater regulations.

o Select priority sites for a field experiment which will evaluate the reliability of monitoring systems.

In this report, we provide background information on the geothermal brine injection problem, and outline each of these tasks in detail. 


\title{
BRINE INJECTION-REVIEW
}

\author{
Characteristics of Geothermal Brines
}

Three characteristics of geothermal brines relevant to their safe handling and disposal are their volume, chemistry and temperature. The large volumes of water involved in geothermal energy production has recently been emphasized by the Imperial Valley Environmental Project. Layton (1980) has estimated that a 100-MW hot water power plant will yield from 7 billion to 23 billion gallons of wastewater a year depending on the initial temperature of the water. Annual disposal of 740 billion gallons of water in the Imperial Valley California would be required if the region's geothermal production reached the predicted level of $6,700 \mathrm{MW}$ of electricity a year for 30 years.

The high temperature brines capable of being used for the generation of electricity are often characterized by high salinity; however, the detailed chemistries can vary considerably from one field to another. Table 1 shows representative fluid samples from a variety of geothermal resources. Fluid quality varies from water of potable quality to fluids that have over 300,000 ppm dissolved solids. Some of the fluids have elevated concentrations of toxic substances such as arsenic boron, lead, copper, and zinc. In general, the high temperature resources are characterized by poorer quality fluids.

Temperatures of the fluids vary markedly from site to site. It is generally considered that electricity generation is not presently economically feasible for resources with temperatures below about $150^{\circ} \mathrm{C}$. Depending on the original in-situ temperature and the energy conversion system used, spent 


$$
-6-
$$

Table 1. Representative Fluid Samples From Selected Geothermal Resources (from Reistad, 1980)

RESOLRCE AREA

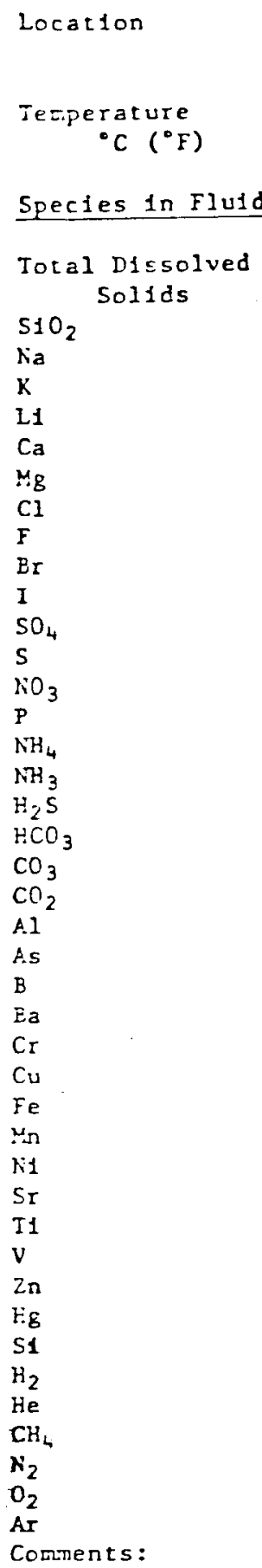

\begin{tabular}{|c|c|c|c|c|c|}
\hline Bolse* & Klakath Fal1s * & Beorave* & Raft River * & Eaca* & Salton Sea \\
\hline ID & $O R$ & $\lambda V$ & ID & NM & CA \\
\hline $80(176)$ & $94(201)$ & $132(270)$ & $146(295)$ & $171(340)$ & $250(482)$ \\
\hline
\end{tabular}

\section{Concentration (ppm or $(\mathrm{mg} / 1)) \star \star \star$}

\begin{tabular}{|c|c|c|c|c|c|}
\hline 290 & & 855 & 1319 & 6898 & $(220,000)$ \\
\hline 160 & 119 & 329 & 91.8 & 835 & $(350)$ \\
\hline 90 & 231 & 214 & 368 & 2010 & $(5,100)$ \\
\hline 1.6 & & 9 & 65 & 541 & $(12,500)$ \\
\hline 0.05 & & Trace & 1.1 & & (220) \\
\hline 1.7 & 36 & & 52 & 36 & $(23,000)$ \\
\hline 0.05 & 0.2 & & 1.9 & & (150) \\
\hline $\begin{array}{l}10 \\
14\end{array}$ & 61 & $\begin{array}{r}50 \\
6\end{array}$ & $\begin{array}{r}611 \\
5.5 \\
<2.5 \\
0.035\end{array}$ & 3770 & $(133,000)$ \\
\hline 23 & 484 & 89 & $\begin{array}{c}63 \\
<0.2 \\
0.19 \\
<0.003 \\
4.53\end{array}$ & $\begin{array}{l}58 \\
2.2\end{array}$ & \\
\hline Trace & & $\begin{array}{l}3 \\
6.1\end{array}$ & & & \\
\hline $\begin{array}{c}70 \\
4 \\
0.2\end{array}$ & 51 & $\begin{array}{r}41 \\
168\end{array}$ & 86.6 & $\begin{array}{r}118 \\
0\end{array}$ & \\
\hline $\begin{array}{l}\text { Minor } \\
0.05\end{array}$ & & 0.2 & & & $\begin{array}{l}(0.04) \\
(1)\end{array}$ \\
\hline 0.14 & & 1 & 0.3 & & $(350)$ \\
\hline 0.2 & & & 0.4 & & $(270)$ \\
\hline Minor & & & & & $(0.6)$ \\
\hline 0.08 & & Trace & & & (8) \\
\hline 0.13 & & & 3.2 & & $(1,300)$ \\
\hline 0.01 & & Trace & 0.08 & & \\
\hline $\begin{array}{l}\text { Trace } \\
0.01\end{array}$ & & & $\begin{array}{l}3.5 \\
1.3\end{array}$ & & $(500)^{(2.4)}$ \\
\hline Irace & & $\begin{array}{l}\text { Trace } \\
\text { Trace }\end{array}$ & & & \\
\hline
\end{tabular}

Trace-Ninor
0.02

0.0054

44

$$
\begin{aligned}
& 0.0016 \\
& 0.065
\end{aligned}
$$

18.51

0.0029

\begin{tabular}{|c|c|c|c|}
\hline $\begin{array}{l}\text { Well name Wending Well } \\
\text { unknown. } \\
\text { Near old } \\
\text { penttentlaty. }\end{array}$ & $\begin{array}{l}\text { Vulcan } \\
\text { Well } 2\end{array}$ & Well RRGE I & $\begin{array}{l}\text { Fell Eaca } \\
\text { II. Flashed } \\
\text { fluid sample. }\end{array}$ \\
\hline
\end{tabular}

3.1

0.62

* Data from Cosner and Apps, 1978.

* Data from Lund et al., 1976.

** Most analyses are for liquid samples only and do not reflect the non-condensible gases. 
geothermal brine is expected to have a temperature of approximately $100^{\circ} \mathrm{C}$. These $100^{\circ} \mathrm{C}$ fluids could be further reduced in temperature by a wide range of direct use applications.

Disposal Methods

Two methods of geothermal fluid disposal are possible. The fluid may be either discharged at the surface into holding ponds or rivers, or it may be injected into subsurface formations. Miller and $\mathrm{Zimmerman} \mathrm{(1980)} \mathrm{have}$ recently summarized the disposal methods at operating geothermal sites (Table 2). The problems mentioned earlier with respect to fluid quality, temperature, and volume have lead a variety of investigators to conclude that in most situations subsurface injection of at least part of the fluid is the only feasible long-term solution.

$\underline{\text { Injection Strategies }}$

While the discussion so far has been oriented toward the environmental problems of disposing of large volumes of hot, potentially hazardous fluids, the environmental issues are in fact only one part of the overall injection issue. In Table 3, we have summarized beneficial and undesirable factors that must be considered in any injection program. An idealized injection strategy would of course maximize the benefits while minimizing the possible undesirable effects.

A cursory examination of the table reveals many possible conflicting objectives. Should the fluid be injected into the producing reservoir? Above 
Table 2. Disposal Methods at Operating Geothermal Sites (from Miller and Zimmerman, 1980)

Site
Larderello, Italy
Wairakei, New Zealand
Otake, Japan
Hatchobaru, Japan
Cerro Prieto, Mexico
Ahauchapan, E1 Salvador
Geysers, USA

$\%$ Injected

20

0

100

100

0

30

20
\% Surface Disposal

80 to surface streams

100 to Waikato River

None

None

100 to evaporation ponds and Sea of Cortez

70 discharged through 86$\mathrm{km}$ long canal to ocean

80 
Table 3. Desirable and Undesirable Factors Influencing the Design of an Injection Program

Desirable

- Mitigate subsidence

- Disposal of waste fluids away from surface water and shallow aquifers

- Maintain reservoir pressures

o Method to extract heat in rock

o Supply of water to producing reservoir
Undesirable

- Interference with heat output of producing well

- Induced seismicity

- Contamination of groundwater resources

- Excessive power requirements to pump fluid

- Reduction of permeability and plugging of wells due to hydrothermal alteration

- Cost of wells

o Cost of monitoring 
the producing reservoir? Below the producing reservoir? How far from the producing wells should the injector wells be located? What volume of fluid should be disposed of per unit time in each well? Many of the beneficial effects require reinjection into the producing reservoir; however, this may result in several of the undesirable effects. The issue of developing injection strategies based on detailed consideration of these factors will require site-by-site analysis. The second requirement for an overall successful injection program is that, given an appropriately designed injection strategy, the fluid must flow predictably once injected into the subsurface formation. A fluid-monitoring system which responds to the movement of the fluid and thereby tests the predictions of reservoir modeling can thus be an integral part of the success of an injection program.

Monitoring Strategies

A monitoring system around a brine injection well is therefore essential not only to comply with water quality regulations, but is also essential to insure that all of the objectives of the injection program are realized. For example, if water supply, heat extraction from the rock matrix, or reservoir pressure maintenance are objectives of the injection program, then fluid flow directions and rates around the well must be consistent with reservoir model calculations. Unpredictable flow could seriously jeopardize the long-term economic feasibility of the power plant. A monitoring system could be used to signal unpredictable flow and lead to the implementation of corrective measures prior to the development serious environmental or production problems. Conversely, if the flow is consistent with the reservoir model calculations, then extrapolations based on the reservoir model are warranted and 
could guide the future resource exploitation program in a manner which is efficient and consistent with environmental regulations.

We can define two types of monitoring procedures to track the movement of fluid around an injection well. One is the direct sampling approach which relies on fluid samples being taken in observation wells or surface waters. The injected brine may have a unique chemical signature which could be detected at the sampling locations or artificial tracers could be added. The alternative procedure relies on observations at remote sites (boreholes or surface measurements) to track the fluid movement.

Table 4 gives the advantages and disadvantages of each approach. Direct sampling has been successfully used to protect water resources (Davis et al., 1980; Kubata and Aosaki, 1976). However, it suffers from high cost if many monitoring wells are required and the fact that it is a relatively late warning system; the injected fluid must arrive at a designated observation point before one learns much about the movement of the injected front. In contrast, a remote monitoring system has many theoretical advantages including a possible lower cost and earlier warning of unpredictable flow patterns. One well-developed example of this approach is monitoring pressure changes induced by injection in nearby wells. Under the right circumstances it is possible to detect pressure effects from injection before the fluids arrive at a given location. Additional methods based on geophysical observations at remote sites could complement pressure monitoring and tracer studies, and remove some of the uncertainty associated with conventional monitoring systems. This could be particularly important in geothermal systems dominated by fracture flow and characterized by complex hydrology. Unfortunately, the technical feasibility of these methods has yet to be established. 


\section{Table 4. Advantages and Disadvantages of Alternative Monitoring Approaches}

Direct Sampling

\section{$\underline{\text { Advantages }}$}

- Demonstrated Technology

which has been successfully

used in a variety of circumstances

o Very precise

Disadvantages

o Could be expensive if many monitoring wells are required

- Late warning system

o If tracers do not arrive at observation point, little is learned about the fluid movement

- Monitor well siting difficult in hydrologically complex reservoirs where valid a priori reservoir model does not exist

- Only measures at a point $\underline{\text { Remote Detection }}$

\section{Advantages}

- Could give an early warning of unpredicted fluid movement

- Relatively cheap if surface measurements and existing boreholes used

- When used in conjunction with reservoir modeling can enhance the reliability of model calculations

- Sense large volume

Disadvantages

- Not a demonstrated technology except for pressure monitoring

- Early attempts to develop additional methods have been largely unsuccessful

- Location and value will be less precise 


\section{Geothermal Injection Summary}

o

Development of hot water geothermal systems requires disposal of large quantities of relatively high-temperature, potentially hazardous fluids.

o Subsurface injection is one of the major long-term solutions to this problem.

- Monitoring of the injected fluid could insure the achievement of all the objectives of the injection program, including meeting the environmental regulations.

o Tracer studies are well developed and can signal the arrival of injected fluid at a given sampling location.

- Pressure monitoring may also be effective in detecting the migration of injected fluids.

0 Additional remote detection techniques could complement tracer studies and pressure methods and provide an early indication of the path of the injected fluid.

- Technical feasibility of using these remote geophysical detection techniques has not yet been rigorously and systematically tested. 
o A proven reliable remote detection procedure, if established, could be more economical than relying completely on tracer studies and pressure methods, both of which require monitor wells.

- A proven reliable remote detection procedure may provide early warning of potential trouble. 


\section{MONITORING APPROACHES - AN EVALUATION}

\section{Regions Surrounding an Injection Well}

In order to evaluate whether remote geophysical techniques can effectively monitor the movement of injected fluid, one must first consider the physical nature of the injection process. This will determine how physical and chemical properties change as a result of injection, what geophysical techniques could be sensitive to the fluid movement, and how the remote measurements must be positioned in order to maximize the possibility of detection.

Flow front. Injection of geothermal fluids into a subsurface aquifer will lead to the outward movement of a fluid or hydrodynamic interface. Depending on a variety of factors (see below), this hydrodynamic front could be marked by a difference in fluid chemistry. The position of the front is controlled by the injection parameters, reservoir characteristics, and spatial position of the injection well relative to other wells in the field. As an example, Kasameyer et al. (1977) have calculated fluid flow patterns within an arbitrary array of gethermal production and injection wells. They assumed horizontal flow within a single, homogeneous, nonleaky, liquid-filled aquifer of uniform thickness and infinite extent. Figure 1 shows the position of the fluid front for a hypothesized injection strategy at the Salton Sea Geothermal Field. Fluid is produced from Magmamax $\sharp 1$ and Woolsey $\# 1$, and $80 \%$ of the

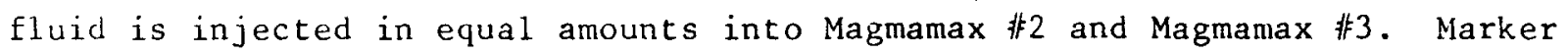
particles start at the injector, and their locations are shown every two years. If we relax the model parameters somewhat and allow the permeability 


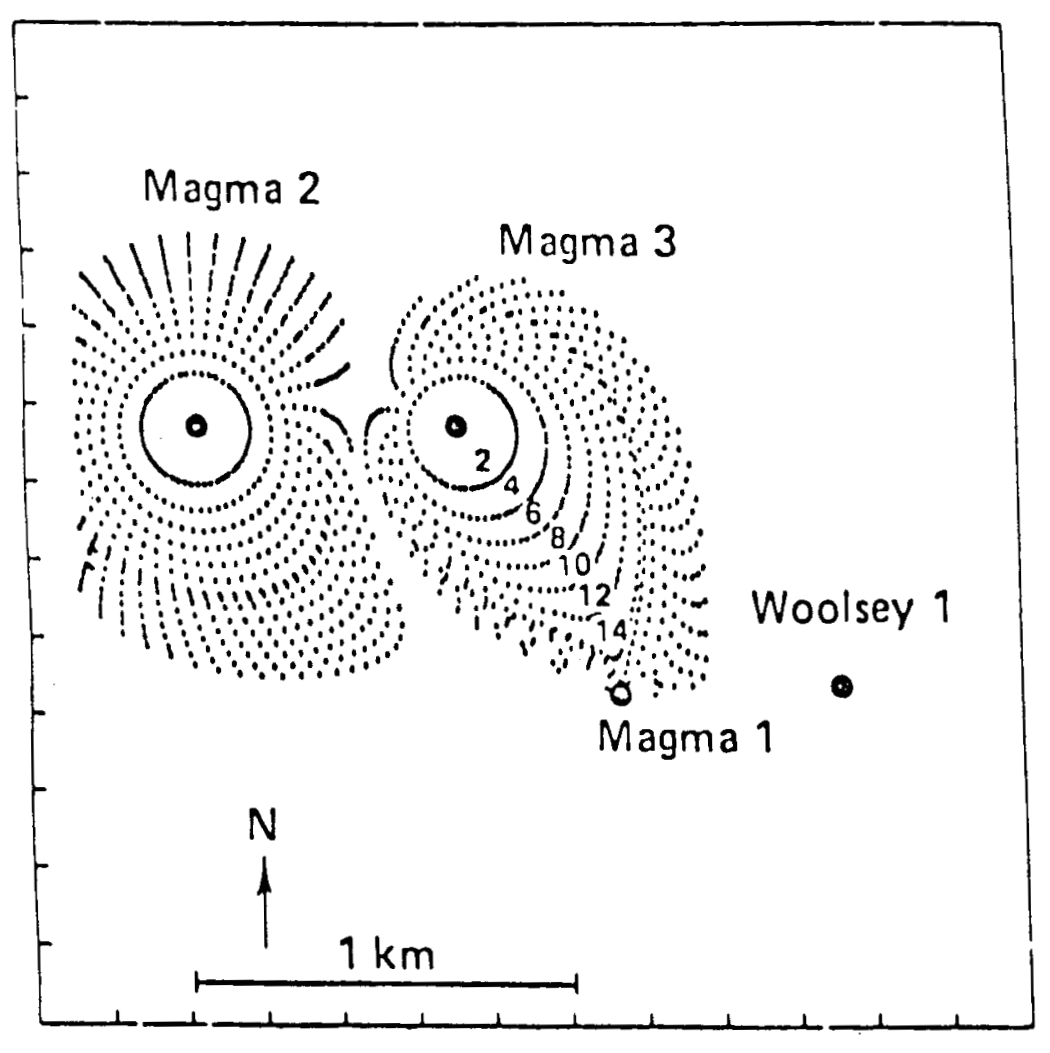

Figure 1. San Dlego Gas \& Electric Geothermal Loop Experimental site. Fluid particle displacenient fronts for isotropic permeablitity. Successive fronts are two years apart.

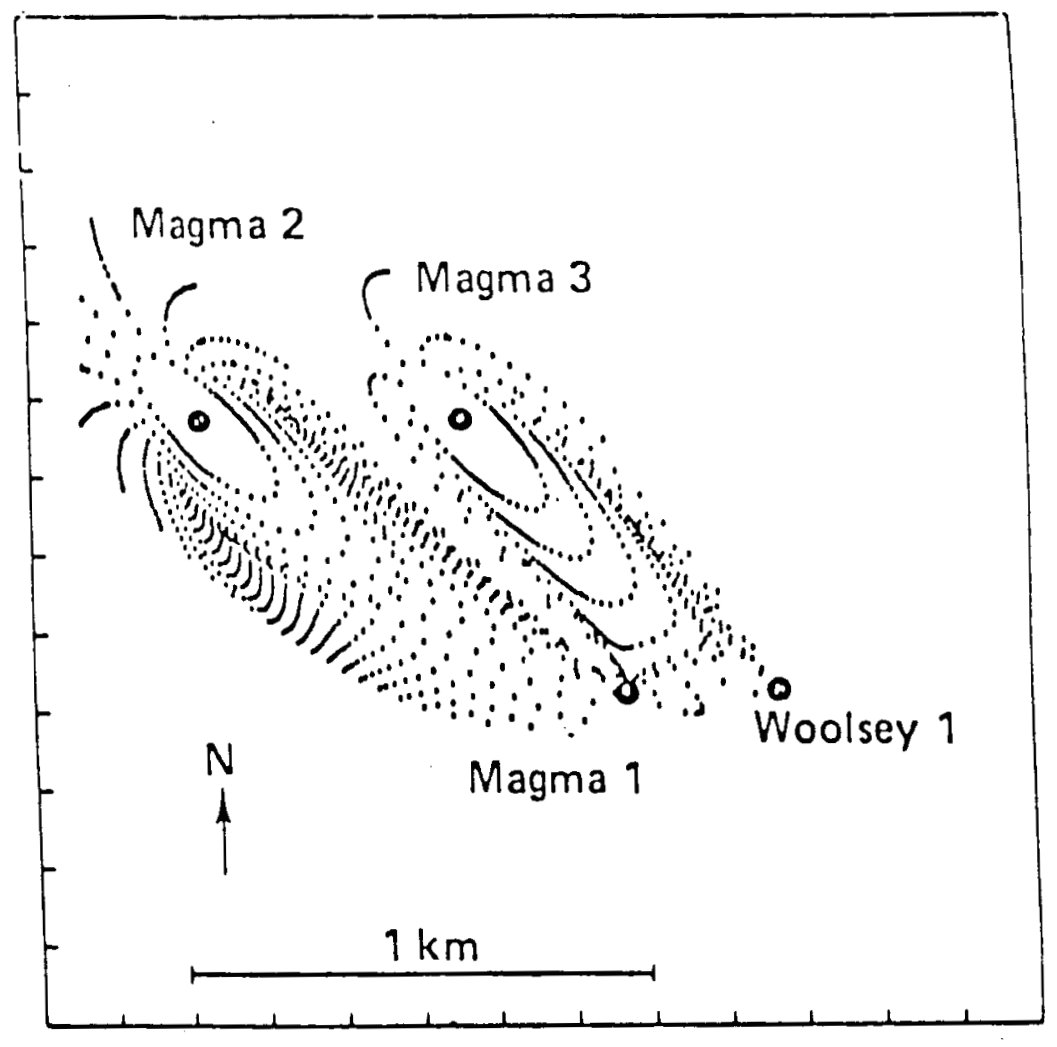

Figure 2. San Diego Gas a Electric Geothermal Loop Experimental site. Fluid particle displacement fronts for anisotropic permeablilty. ( $k_{N H}=9 k_{N E}$ ) successive frunts are two years apart. 
to vary spatially as might be expected in the complex deltaic environment, then the flow fronts are altered (Fig. 2). Two points are to be made from this simple analysis. First, the fluid front can move substantial distances in relatively short time frames. Second, the pattern of the front can be quite complex, reflecting not only production and injection strategies but also the complex three-dimensional distribution of connected porosity and permeability around the well.

Thermal Front. A therwal front around each injector well separates regions of cooled rock and fluid from the hot reservoir (Bodvarrson, 1972; Kasameyer and Schroeder, 1976; Hanson, 1978) (see Fig. 3). Some insight into the nature of this thermal front has been achieved through simple analytical solutions which ignore factors which spread the boundary out. A steep temperature front moves through the system with no change in shape with time and with a lower velocity than the fluid front (Fig. 4). Ahead of the temperature front, the reservoir retains its initial temperature. Behind the front, enough heat has been taken from the rocks to cool them to the injection temperature. Solutions for both porous flow and fracture flow have been developed which give the velocity of the thermal front and a description of the temperature field in the vicinity of an injection well.

Pressure Regime. An important aspect of the fluid injection problem is the influence of such injection on the state of pore pressure and effective stress in the reservoir. In order to calculate the distribution of fluid pressures, it is necessary to have knowledge of the nature of the flow system (porous vs. fractured), the vertical and horizontal variation of permeability, and the bulk modulus of the reservoir rock. It is this pressure distribution which, 


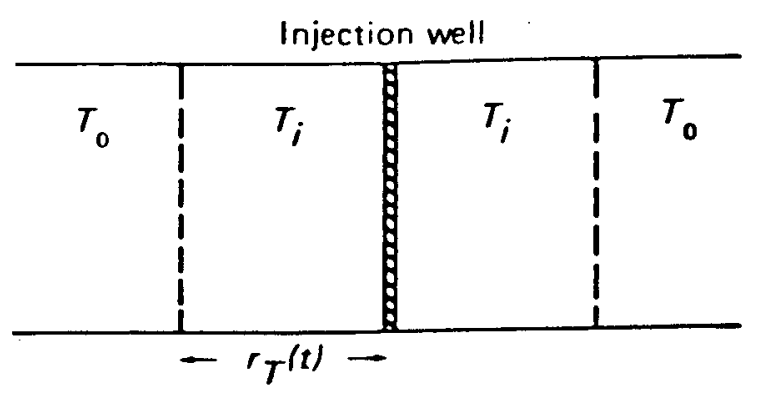

Figure 3. Cross section of permeable layer, showing temperature front at distance $r_{\mathrm{T}}(t)$ from injection we11 (From Kasameyer 1977)

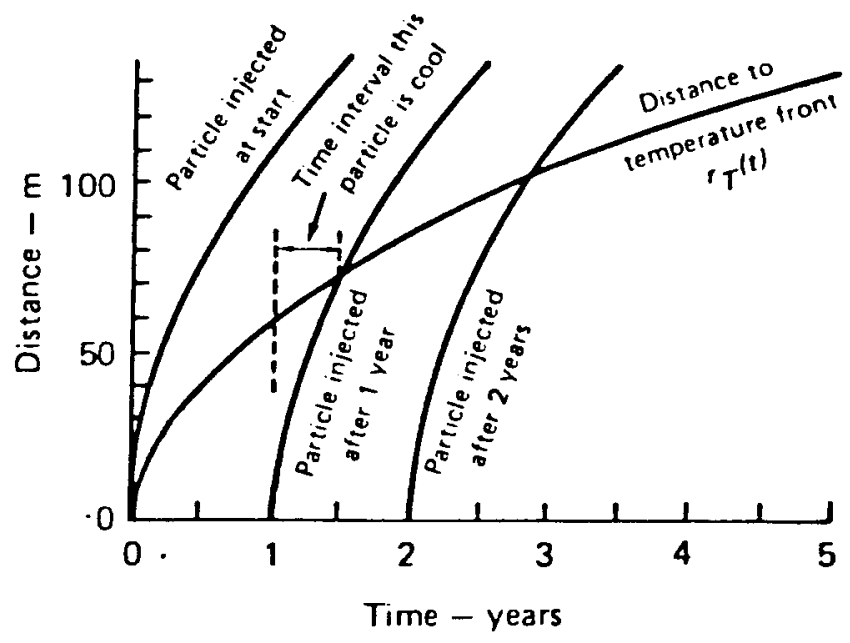

Figure 4. Location of temperature front and fluid particles injected at different times for a radial flow example (From Kasameyer 1977) 
of course, controls the flow patterns discussed earlier. If flow is restricted to a porous medium and the permeability and rock compressibility distribution is known, the calculation of the induced pressure distribution is straightforward. If there is spatial variation in permeability, as in the case of thief sands, this pressure distribution can change significantly (Jorda, 1980). If the flow patterns are controlled by fractures, the pressure distribution can also be altered considerably. In such a case, the pressure distribution is a function of not only the fracture distribution but also the degree to which the fractures are able to deform as the stress level changes (Noorishad et al., 1977). Generally, we can expect a pressure gradient to exist beyond the flow front, producing a region of moving original pore fluid.

Porosity and Permeability Changes. Several competing effects around an injection well can be expected to cause changes in the porosity and permeability. An increase in pore pressure should produce an expansion effect, causing a region surrounding the injection well to have a higher porosity and perhaps permeability (see Appendix A). In a porous medium, this increase in pore pressure could cause some pore space closed by deposition to reappear. In a Eractured medium, this increase in pore pressure could cause deformable fractures to open.

Other effects around an injector could enhance or negate these changes. The minerals in the reservoir rock can react with the injected fluid, creating new minerals and altering others. These changes can lead to net solid volume increases which tend to plug the formation around the injector, or net solid volume decreases which tend to increase the reservoir permeability (Taylor et al., 1978). Evaluation of which process is dominant will require site-by-site 
analysis of injected fluid and reservoir temperatures and chemistries. It will be strongly dependent on techniques employed at the surface to remove particulate matter and dissolved calcite and silica.

Hydrofracturing and Fluid Turbulence. It has been repeatedly shown that high fluid pressures can lead to a reduction in effective stress and cause renewed failure on existing zones of weakness. This is not expected to be a major factor in programs injecting fluid at relatively low pressures. However, the possibility exists that microfracturing on a small scale around the injection well could occur. Morse and Schroeder (1977) analyzed the pressure response of two wells in the Salton Sea Geothermal Field during a freshwater injection test, and showed that hydraulic fracturing probably occurred. The field data for downhole pressure fell within the range of theoretically predicted bottom hole fracturing pressures, and the pressure flow rate relationship was consistent with a period of hydraulic fracturing. Catastrophic hydrofracture will, of course, be manifested by an immediate pressure drop at the injection well. Depending on the fluid pressures and the fracture permeability around the borehole, turbulent flow of injected fluid might also be expected. Hydrofracturing, turbulence, and other inelastic strain effects might release characteristic acoustic emissions in the area of elevated pore pressure around the well. 


\section{Idealized Injection Well}

Figure 5 shows a schematic diagram of an injection well with associated fluid and temperature boundaries. As an example, consider an injection program which reinjects fluid of $100^{\circ} \mathrm{C}$ back into a producing reservoir with a temperature of $250^{\circ} \mathrm{C}$. A fluid front moves out from the injection well. A thermal front moves out at a lower velocity than the fluid because the fluid is slowly heated by the relatively hot reservoir rock. Also pore pressure will increase, producing a region of increased porosity surrounding the well. Additional changes in porosity and permeability due to reactions between the injected fluid and the host rock may or may not occur depending upon chemistry differences, temperature differences, and kinetic considerations. If the Reynolds number is high enough, a region of turbulent flow might occur around the borehole. Depending on injection pressures and reservoir permeability, seismic emissions could occur reflecting the development of microfractures. These major regimes are schematically illustrated in Figure 6 . Depending on conditions, the boundaries could be fairly sharp or very diffuse.

Factors Controlling Types of Anomalies Present at a Given Site

The above analysis identifies the general processes occurring in the region surrounding an injection well. Whether or not these phenomena produce detectable anomalies at a given site is controlled largely by the details of the injection program and the characteristics of the reservoir.

Alternative Injection Programs. Three alternative injection strategies could be undertaken at a geothermal facility. 
Figure 5. Idealized Zones Surrounding an Injection We11.

$\begin{array}{ll}\text { Injection } & \text { Zone of Injected } \\ \text { Well } & \text { fluid and temperature }\end{array}$

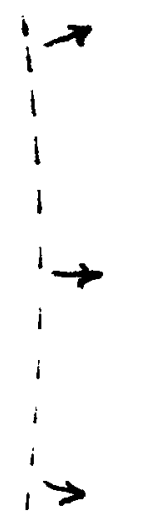

Thermal

Front
Zone of Injected

fluid and original

aquifer temperature

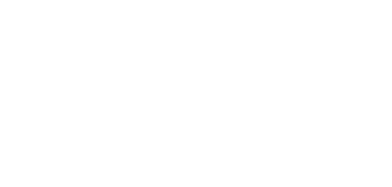

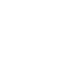
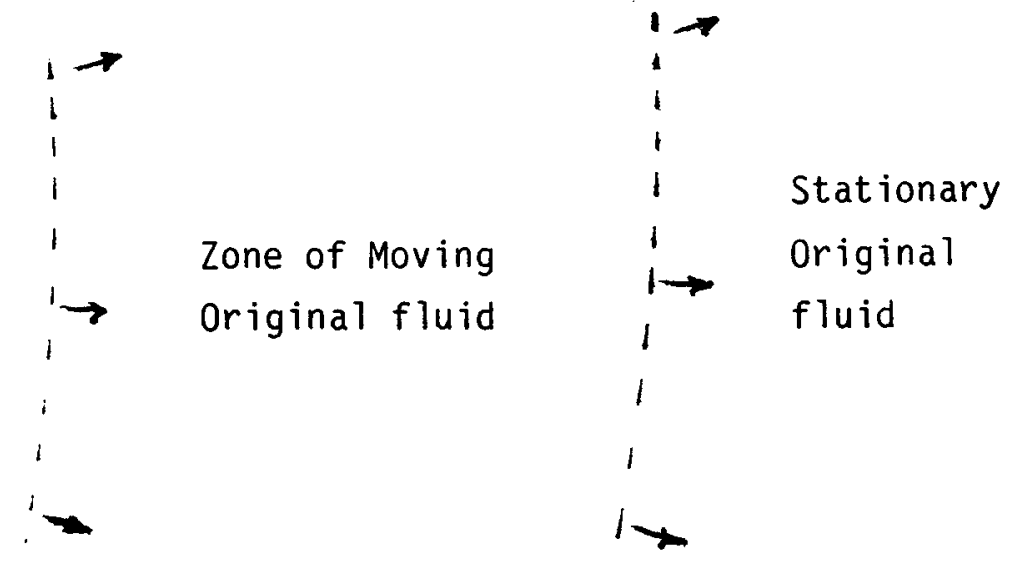

N

Front 


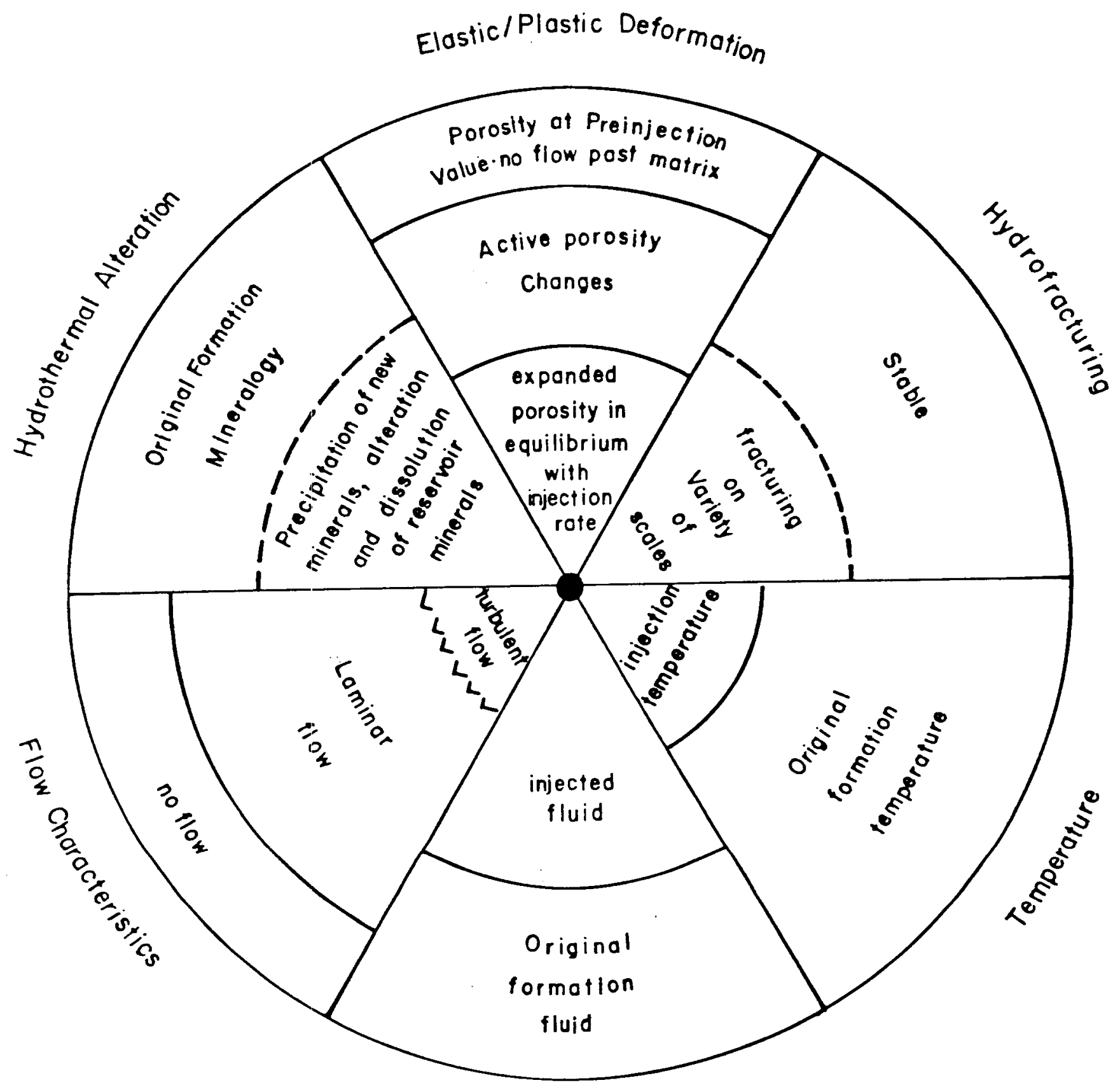

Fluid Composition

Figure 6. Major Regimes Radially Surrounding an Idealized Injection Well. For illustration sake, the boundaries are indicated as sharp. Any of these zones or boundaries where there is a physical change could provide a target for remote detection. The relative positions of boundaries in different quadrants would depend on the specific case. 
Case 1. Inject into an unsaturated region

In this case, fluid enters existing pore space, or perhaps a fracture pattern is generated to accommodate the injected fluid. Anomalies would be generated by the fluid as well as by the dynamic processes associated with possible hydrofracturing. Albright (1977) has recently reported considerable success in determining the volume affected by fluid injection in the Hot Dry Rock Project using microseismic, induced potential, and acoustic signal investigations.

\section{Case 2. Inject into aquifer distinct from the producing zone}

In this case, fluid replaces the existing pore fluid. Anomalies in this case could be produced by temperature differences across the thermal front, chemistry differences across the fluid front, and dynamic processes associated with injection. If a high-salinity brine is injected into a shallow aquifer, the anomalies due to chemistry differences could be quite significant. This type of injection would not achieve many of the desired objectives of an injection program; however, it could be a major strategy if production well temperatures are threatened by injection into the producing reservoir or the economics of pressure injection require use of an acceptable shallow aquifer. 


\section{Case 3. Inject into the producing aquifer at some distance from the producing field}

This is a likely scenario for injection because it is consistent with the major goals of many injection programs. Anomalies in this case could be produced by a temperature difference across the thermal front, a possible minor chemistry change across the fluid front, and the dynamic processes associated with injection, including flow characteristics and microfracturing of the host rock. This scenario will help maintain fluid pressures near production wells and thereby help to maintain porosity and permeability near production wells.

$\underline{\text { Reservoir Characteristics }}$

Porous Flow vs. Fractured Flow. The type of flow permeability could affect a variety of factors relevant to injection, including the position of the thermal, fluid, and pressure fronts, the presence or absence of hydrofracturing, and the type of flow regimes.

Permeability Distribution. The idealized injection problem considered, so far, has assumed horizontal flow away from the injection well reflecting a horizontally stratified reservoir. Alternative permeability distributions are, of course, possible and could significantly affect the fluid movement. As an example, if the perneability is uniform in all directions, the denser injected fluid would tend to sink initially until it is heated, and perhaps change the possibility of detecting its movement by remote observations at the surface. We can define several alternative permeability distributions, 
including homogeneous, horizontally stratified and radially anisotropic. Each of these could control the flow and thereby influence the possibility of remote detection.

In order to assess accurately whether the idealized anomalies depicted in Figure 6 are likely to be observed at a given site, one must analyze the injection scenario/reservoir model combination most representative of the site. Initially, we will concentrate on Case 3 injection strategy and horizontally stratified aquifers. Given this situation, we will estimate the changes in stress, strain, and bulk physical properties as a function of position and time in the region surrounding an injection well. These estimates will be used to evaluate which remote detection approach is feasible in a given situation.

$\underline{\text { Remote Monitoring Approaches }}$

The second step in the evaluation procedure is to assess whether the expected anomalies are capable of being detected at remote sites. Several geophysical techniques will be evaluated with respect to their ability to note the presence of the injected brine. The evaluation procedure will, in general, follow a standard format which includes the following:

1) Review of related work

2) Definition of critical questions which must be answered in order to complete the evaluation

3) Evaluation of the approach

4) Recommendations for field experiment. 
Several approaches will be considered, including microseismic events, acoustic transmission characteristics, precision microgravity, D. C. resistivity, induced potential, electromagnetic wave propagation, self-potential method, magnetotellurics, precision leveling, horizontal distance meters, extensometers, and tiltmeters. A brief description of the various techniques under consideration is presented in Appendix A. Early emphasis will be on the general feasibility of monitoring. Assuming that the analysis indicates the possible utility of certain techniques, later analysis will be concerned with instrumentation and experimental design questions. 


\section{BRINE INJECTION MONITORING PROJECT - OVERVIEW}

The LLNL Brine Injection Monitoring Project will involve three major tasks in FY81. The first task and major objective of the program for this year is to evaluate the range of approaches available to monitor the movement of injected fluid. As noted earlier completion of this task will require evaluation of three major questions:

1) What types of anomalies are likely to appear in the region around an injection well? Because the answer to this question is dependent on the injection strategy and the reservoir characteristics, it will have to be evaluated for a range of scenarios representative of hot water geothermal systems.

2) What geophysical techniques are likely to be sensitive to these anomalies? Given an anomaly of a certain contrast and size, computer code calculations will be used to assess what accuracy and spatial locations of measurements are required to resolve the presence of the anomaly and to determine the uniqueness (or non-uniqueness) of the interpretation.

3) What instrumentation will be required to achieve the desired monitoring? Emphasis here will be on measurement accuracy, measurement strategy, and compatability of the equipment with expected field conditions.

Deliverable from this phase of the study will be a multi-authored document that assesses the possibility of remotely monitoring fluid movement. 
The second task is concerned with preparation for an eventual field experiment. If some monitoring approaches are deemed feasible in the above evaluation, then a field experiment to rigorously test a complete monitoring system would be necessary. Selection of a field site will be based on background data, accessibility, and suitability for testing favored experimental procedures. It may be necessary to choose more than one site. Initially, a priority list of desirable sites will be made; the permission to use these sites would then have to be obtained.

The above two tasks are designed to produce a technically rigorous evaluation of remote monitoring approaches. In order to insure that the technical results are practical and useful, a third task for FY81 has been identified. This task was not specifically dealt with in the January, 1981, Field Task Proposal. It is concerned with the overall question of environmental regulations and geothermal injection programs. Critical questions considered in this task include:

o What regulations are now in place that apply to injection?

o What technologies are available to comply with regulations?

o Can these existing approaches satisfy the regulations in a reliable and economic way?

o Are additional approaches needed and/or useful?

o If feasible, how would a remote monitoring approach be incorporated into the overall monitoring system? 
Deliverable from this task would be a document summarizing what is presently required and being done and assessing whether additional approaches are worth pursuing.

The relationship between the three tasks, and the field experiment is schematically illustrated in Table 5. The monitoring approach evaluation and the review of regulations will be used to determine whether a field test is warranted. 
Table 5. Overview of Brine Injection Monitoring Project

Task:

Evaluation

of

Monitoring Approaches

Results

Preliminary Assessment of Whether Geophysical Techniques can Monitor the Movement of Injected Brine
Task:

Review of Groundwater

Regulations and

Injection Programs

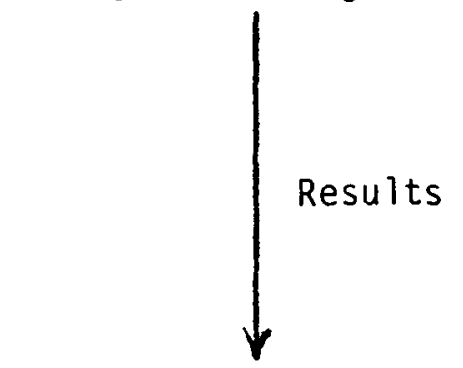

Assessment of Whether Additional Monitoring

Approaches are Necessary or Desirable

If these results warrant continued effort, plans

for a field experiment will

be developed.

TASK

FIELD EXPERIMENT

- Site Chosen

- Characterization of Site

- Experimental Design Developed

- Field Test Performed

results

Rigorous Test of Complete Monitoring System

Final Recommendations for Monitoring System

What is the "best" monitoring system

for geothermal injection wells? 
$\underline{\text { SUMMARY }}$

The development of an economic and reliable system to track the movement of injected brine would greatly facilitate the rapid production of energy from hot water geothermal systems. Such a system, when used in conjunction with reservoir modeling, would not only reduce the cost of meeting all environmental regulations but would also allow the resource to be exploited in a manner consistent with the long-range development plans.

The technology available today to achieve this goal includes direct sampling in witness wells, pressure observations in surrounding wells, and borehole measurements that indicate at what level the brine is entering the subsurface formation. A monitoring system based solely on these approaches can be an adequate and reliable solution. However, significant shortcomings are identifiable. First, direct fluid sampling and pressure measurements can be expensive if many monitor wells are required. Second, in geothermal systems characterized by fracture permeability or strongly anisotropic flow patterns, it is possible for the injected fluid to pass beyond observation points without detection.

A remote detection system could complement the existing methods and be incorporated into a total brine management program which includes witness well techniques and reservoir modeling. The technical feasibility of remote monitoring has yet to be established, and there is no question that successful remote monitoring approaches will be difficult to develop. These methods have been applied successfully to related problems, indicating that the approach is worth pursuing. 
- Ohtake (1974) has noted the presence and position of microseismic events associated with water injection at the Matsushiro geothermal field in Japan.

- Isherwood (1977) and Hunt (1977) have reported precision gravity measurements that reflect geothermal reservoir depletion at the Geysers and Wairaki Geothermal Field.

- Mink (1981, personal communication) has observed elevation changes at the Raft River Geothermal site associated with fluid injection.

- Albright (1977) has used microseismicity, induced potential, and acoustic signal transmission to outline the region occupied by fluid in the Dry Hot Rock Project.

- A wide variety of surface resistivity studies have been used to trace contaminated groundwater plumes associated with landfill sites and other point sources (Rogers and Kean, 1980; Risk, 1980).

- Self-potential anomalies associated with geothermal sites have been noted, and may be caused by flow of subsurface fluids (Corwin and Hoover, 1979).

- Field experiments associated with in-situ coal gasification experiments have shown that high-frequency electromagnetic probing can be used to monitor the rate and direction of flow of injected saline fluids (Lytle et al., 1979). 
This list is not meant to be exhaustive and the selected examples are certainly not direct analogues to the brine injection problem in all respects, but they do indicate that remote monitoring of fluid movement is possible under a range of geological conditions.

Our program for FY81 is concerned with the technical evaluation of remote monitoring approaches. If the preliminary analysis is favorable and if an analysis of environmental regulations indicates the desirability of complementing existing tracer and observation well approaches with remote approaches, a field test will be proposed for FY 82. The field test would be designed to rigorously test a complete monitoring system. 


\section{REFERENCES}

Albright, J. N., Induced Microseismicity, Induced-Potential Measurements and Acoustic-Attenuation Measurements, in Proceedings of the Second NATO-CCMS Information Meeting on Dry Hot Rock Geathermal Energy, 1977.

Bodvarsson, G., Thermal Problems in the Siting of Reinjection Wells, Geothermics $1,63-66,1972$.

Burkhard, N. R., Resolution and Error of the Back Projection Technique Algorithm for Geophysical Tomography, Lawrence Livermore National Laboratory, Rept. UCRL-52984, 1980 .

Corwin, R. F. and D. B. Hoover, The Self-Potential Method in Geothermal Exploration, Geophysics 44, 226-245, 1979.

Davis, S. N., G. M. Thompson, H. W. Bentley and G. Stiles, Ground-Water Tracers-A Short Review, Ground Water 18 14-23, 1980.

Hanson, J. M., Predicting Thermal Effects of Injected Effluents, LLL Geothermal Energy Development Program, Highlights Report, Earth Sciences Division, Lawrence Livermore National Laboratory ATHS/ISP-13, 1978.

Hunt, T. M., Recharge of Water in Wairakei Geothermal Field Determined from Repeat Gravity Measurements, New Zealand J. Geol. \& Geophys. 20, 303-317, 1977.

Isierwood, W., Geothermal Reservoir Interpretation from Change in Gravity, in Proceedings Third Workshop Geothermal Reservoir Engineering, Stanford University, December, 1977.

Jorda, R. M., Predicting Injector Performance at the Proposed Magma-SDG\&E Fifty Megawatt Geothermal Power Plant, Sandia Laboratories, SAND79-7128, 1980 .

Kasameyer, P., Thermal History of Injected Effluents, in LLL Geothermal Energy Program Status Report 1976-77, Lawrence Livermore National Laboratory, Rept. UCRL-50046-76, 1977.

Kasameyer, P. and R. C. Schroeder, Thermal Depletion of a Geothermal Reservoir with Both Fracture and Pore Permeability, Lawrence Livermore National Laboratory, Rept.UCRL-77323, 1976.

Kasameyer, P., L. Thorson, C. McKee, Modeling Thermal and Flow Fronts for Arbitrary Well Arrays, Geothermal Resources Council Trans. 1, 163-165, 1977.

Kubota, K. and K. Aosaki, Reinjection of Geothermal Hot Water at the Otake Geothermal Field, in Proceedings Second United Nations Symposium on the Development and Use of Geothermal Resources, 1379-1383, 1976. 
Layton, D. W., An Assessment of Geothermal Development in the Imperial Valley of California; Environment, Health, Socioeconomics, and Environmental Control Technology, Executive Summary, Department of Energy, DOE/TIC-11308, 1980 .

Lytle, R. J., D. L. Lager, E. F. Laine, J. D. Salisbury, and J. T. Okada, Fluid-Flow Monitoring Using Electromagnetic Probing, Lawrence Livermore National Laboratory, Rept. UCRL-83444, 1979.

Miller, F. L. and D. E. Zimmerman, Compilation of Failure Data and Fault Tree Analysis for Geothermal Energy Conversion Systems, Interim Report, U.S. Environmental Protection Agency, Las Vegas, Nevada, 1980.

Morse, J. G., and R. C. Schroeder, Case Studies: Injection Tests in LLL Geothermal Energy Program Status Report 1976-1977, UCRL-50046-76, 1977.

Noorishad, J., P. A. Witherspoon, and Y. N. T. Maini, The Influence of Fluid Injection on the State of Stress in the Earth's Crust. in Proc. Symp. Percolation Fissured Rock-Int. Soc., Roch Mech. T2-H, 1-11, 1972.

Ohtake, M., Seismic Activity Induced by Water Injection at Matsushiro Japan, J. Phys. Earth 22, 163-176, 1974.

Owen, L. B. and R. Quong, Improving the Performance of Brine Wells at Gulf Coast Strategic Petroleum Reserve Sites, Lawrence Livermore National Laboratory, UCRL-52829, 1979.

Reistad, G. M., Direct Application of Geothermal Energy, Department of Energy, DOE/ET/20501-T1, 1980 .

Risk, G. F., Tests of the Applicability of Electrical Prospecting Methods for Detecting Underground Seepage of Pulp and Papermill Effluent at Kinleith, Report No. 170, Geophysics Division Department of Scientific and Industrial Research, New Zealand, 1980.

Rogers, R. B. and W. F. Kean, Monitoring Ground-Water Contamination at a Fly Ash Disposal Site Using Surface Electrical Resistivity Methods, Ground Water $18,472-478,1980$.

Taylor, R. W., D. D. Jackson, I' Wolery, and J. A. Apps, Geochemistry, in Geothermal Resource and Reservoir Investigations of U.S. Bureau of Reclamation Leaseholds at East Mesa, Imperial Valley, California, Lawrence Berkeley Laboratory, Rept. LBL-7094, 1978. 


\section{APPENDIX A - BRINE INJECTION MONITORING APPROACHES}

I. Seismology

Seismology offers a number of approaches to define the reservoir configuration and the brine injection front. Techniques include monitoring microselsmicity for location and mechanisms, defining changes in rock properties through variations in $P$ and $S$ wave velocities, and attenuation of $P$ and $S$ waves in the reservoir region. An experiment for defining the brine reinjection zone will have to be carefully designed for the most promising methods. Parameters include the frequency, bandwidth, dynamic range, density of seismic stations, depth of geophones, desirability of active experiments and calibration explosions. The usefulness of each approach strongly depends on the type of reservoir encountered. In addition, new approaches to processing and combining the data are important avenues of investigation. In particular, joint inversions of $F^{\prime}$ and $S$ wave data for velocity structure, event location, and $Q$ are possible.

\section{Microseismicity}

Monitoring microseismicity involves a number of important questions: the location of events and their temporal correlation with injection parameters, focal mechanisms and relationship to structure and injection pressure, magnitudes and moments, relationship of occurrence and detection capabilities, frequency content of arrivals, noise (e.g., low frequency) and its relationship to injection and withdrawal, necessity for calibration events, and data processing requirements. From these points one observes the importance of equipment and processing capabilities. 
Attenuation of $\mathrm{P}$ and $\mathrm{S}$ Waves

Both attenuation of $P$ and $S$ waves and differential attenuation may provide some constraints on the configuration of the injection front. The frequency, bandwidth, and dynamic range of the recording system are again important considerations that we will consider. The possibility of velocity changes may strongly depend on the type of reservoir and the local geology.

Velocity of $\mathrm{P}$ and $\mathrm{S}$ Waves

Differential velocity changes between $P$ and $S$ waves may occur upon injection of the brine. They have been observed for steam reservoirs, but changes in $\mathrm{Vp} / \mathrm{Vs}$ are not likely in hot water systems. These observations involve an active experiment using seismic sources or cross hole methods.

\section{Elevation of Land Surface}

Measuring elevation change may help greatly in indicating how regional groundwater flow patterns have been perturbed by injecting brine at depth. Elevation change is the expression at land surface of the net sum of the vertical components of volume strain within underlying strata.

The U.S. Geological Survey has developed a field-based method of parameter evaluation at the scale of a regional confined aquifer system by using field measurements of elevation change (both rising and lowering land elevation) and field-observed changes in hydraulic head. Change in the volume of voius (both in fractured rock and in sedimentary material is directly 
related to the volume and pressure of outward moving injected fluid and may indicate the location of the brine front itself. It may be feasible to extend the U.S.G.S.'s field technique and apply it to the case of fluid injection.

I suggest the following 1 ine, of reasoning to investigate this approach. In terms of increase in porosity, one can specify three basic zones surrounding an injection well. Closest to the well is a zone where a new expanded porosity has reached equilibrium with the injection rate. Within this region the velocity of liquid $v_{\ell}$ is essentially steady past nonmoving solids, namely,

$$
\begin{array}{r}
\underline{\nabla} \cdot\left(\underline{\mathrm{n}}_{\ell}\right)=-\mathrm{A} \\
\underline{\mathrm{v}}_{\ell} \neq \underline{\mathrm{v}}_{\mathrm{s}}=0
\end{array}
$$

where $\mathrm{n}$ is porosity, $\underline{\mathrm{v}}_{\mathrm{s}}$ is the velocity of solids, and $\mathrm{A}$ is a function of the rate of compression (or expansion) of individual constituents. For saturated porous material,

$$
A \equiv\left(n / \rho_{\ell}\right) D \rho_{\ell} / D t+\left[(1-n) / \rho_{S}\right] D \rho_{S} / D t
$$

where $\rho_{i}$ is the density of the $i^{\text {th }}$ constituent $(i=\ell, s)$. For conditions of steady flow A can be considered negligibly small.

Farthest from the well is a zone where there is no hydraulic gradient, liquid is not flowing past the solid matrix, and in the neighborhood of a point fixed in the solid matrix the porosity has remained at its preinjection value, namely, 


$$
\begin{gathered}
\underline{\nabla h}=0 \\
\underline{\nabla} \cdot \underline{\mathrm{v}}_{\ell}=-\mathrm{A} \\
\underline{\mathrm{v}}_{\ell}=\mathrm{v}_{\mathrm{s}} \neq 0
\end{gathered}
$$

where $h$ is the induced change in hydraulic head.

For both zones we write

$$
\mathrm{Dn} / \mathrm{Dt}=0
$$

Behavior within the intermediate zone is more complex. Nonequilibrium conditions of fluid flow and correspondingly active porosity change occur in this zone. We write

$$
\begin{aligned}
& \underline{\nabla} \cdot\left(\underline{n v}_{\ell}+(1-n) \underline{v}_{s}\right)=-A \\
& \underline{v}_{\ell} \neq \underline{v}_{s} \neq 0 \\
& D n / D t \neq 0 \\
& \underline{\nabla} \cdot\left(k \rho_{\ell} g / n_{\ell} \underline{\nabla h} \neq 0\right.
\end{aligned}
$$

where $k$ is intrinsic permeability, $g$ is gravitational acceleration, and $\eta_{\ell}$ is the liquid viscosity. 
The intermediate zone is bounded on the inside by an expanding inner zone characterized by $\underline{v}_{s}=0$ and on the outside by a retreating outer zone characterized by $\underline{\nabla} \cdot \underline{v} \cdot \mathrm{s}=-\mathrm{A}$.

The brine that is in the process of being injected at volume rate $Q$ has a Front somewhere within the intermediate or inner zones. It is likely that further analysis will more closely define the mathematical location of the brine front. The land surface can be considered to lie at least for a period of tinte within the moving outer zone. If it is technically feasible to measure at least a component of $\underline{v}_{s}$ or cumulative displacement $\int_{0}^{t} \underline{v}_{s} d t$, we may have a clue as to where the leading boundary of brine is.

It is instructive to make in passing some preliminary estimates of cumulative elevation gair $S$ as a function of injection rate $Q$. For the sake of illustration we neglect the term $A$ that appears in some of the foregoing equations. This is justified for steady flow in general and is justified for transient flow whenever Dn/Dt of (10) is much larger than $A$ of (3).

For simplicity we assume movement in the outer zone (where fluid is not passing the solid matrix) is radially outward with spherical symmetry. Hence, for large $R$ this yields the relation

$$
\underline{v}_{1}=\underline{v}_{s}=\frac{Q}{4 \pi} \frac{R}{R^{3}}
$$

where $R$ is the distance from the injection point to a point of interest in the outer zone. The vertical component of $v_{s}$ at land surface can be expressed by 


$$
\mathrm{dS} / \mathrm{dt}=\frac{\mathrm{Q}}{4 \pi} \frac{\mathrm{z}}{\left(z^{2}+r^{2}\right)^{3 / 2}}
$$

where $z$ is the depth below land surface to the injection point and $r$ is the distance along the nearly flat land surface from the injection well to the instrument where elevation change is being measured. Idealized horizontal movement can also be estimated. Cumulative rise of land surface can be expressed approximately by

$$
S=\frac{z}{4 \pi\left(z^{2}+r^{2}\right)^{3 / 2}} \int_{0}^{t} Q d t
$$

It is important to note that we have tacitly required a nucleus of strain to develop underground only at one point--namely at an injection point. Hence, the foregoing solution is applicable only for movement due to a single nucleus of strain at one point. If we integrate this solution over the expanding finite volume of the fully strained inner zone that surrounds the injection well, we shall accomplish two things. First, the estimates of dS/dt and $S$ will be more realistic, and second, we may get a clue as to how the rate and shape of growth of the inner zone of equilibrium strain is reflected at land surface. The existence of nonmoving, impermeable basement rock must also be accounted for. This is the line of reasoning that may allow us eventually to find a causal relation between induced $S$ and the migration of injected brine.

State-of-the-art instruments for measuring surface movement include extremely accurate horizontal distance meters and precision leveling. Measurement of time-dependent cumulative subsurface displacement is of great 
importance, if feasible. Vertical extensometers are refined borehole instruments that directly measure cumulative vertical expansion (and compression) relative to the land surface. There does not yet exist a comparable instrument that directly measures horizontal displacement at depth with ease, precision, and economy.

\section{Geotomography (E\&M and Seismic Transmission)}

Geotomography is a remote sensing technique which produces a two-dimensional image of the area between two boreholes. Using rf electromagnetic wave propagation between two boreholes, an image indicative of either electromagnetic attenuation or permittivity contrast can be generated. If seismic waves are used, the resulting image will be indicative of either acoustic attenuation or rock elastic parameters. Tomographic data is collected by transmitting between the boreholes along many different paths. Different ray paths will sample different parts of the region between the holes. From data along the multiple ray paths, an iterative algorithm can generate a two-dimensional image of the area sampled by this technique. Burkhard (1980) has recently made an analysis of the resolution and error of the back projection technique algorithm for geophysical tomography. His approach can be used to evaluate what contrast in properties and measurement strategies would be necessary to detect the brine front.

For liquid reinjection, if the liquid has sufficiently different electrical conductivity (or different permittivity), then the front of that injected material can be monitored. With seismic geotomography, both P-wave and $\mathrm{S}$-wave propagation should be considered. 
IV. D. C. Resistivity and Induced Potential

A variety of electrode arrangements are possible for resistivity measurements including surface-to-borehole arrays and borehole-to-borehole arrays .

A computer code has been developed at LLNL for the purpose of estimating the observed anomalous electrical potential due to a subsurface body of arbitrary shape and electrical conductivity contrast. The code has the flexibility of positioning the current and potential probes either on the surface, or downhole, or both. We plan to use this code to determine the sensitivity of D. C. resistivity and induced polarization techniques for mapping the flow front of injected brine under a variety of situations. These include (1) sensitivity to conductivity contrast between the injected brine and reservoir fluid, (2) sensitivity to depth of injection zone, (3) sensitivity to current/potential probe spacing and location, and (4) sensitivity for detection of brine migration to a shallower aquifer. Based on these analyses, a statement regarding the appropriateness of D. C. resistivity and I. P. methods to mapping brine injection fronts, and possible groundwater aquifer contamination, will be made.

\section{Gravimetry}

Reinjection of spent brine can change the bulk density of formations into which it is injected in two ways. If the injected material damages the formation, the total porosity may be increased by fracturing, and the bulk density is then decreased. If the brine has substantially more dissolved solids than 
the original formation fluid, the density is increased. It may be possible to detect these density changes by gravimetry, either from the surface or from boreholes. We have computer programs that calculate the gravity caused by subsurface structures, and we are familiar with the precision available for surface and subsurface gravity measurements. Therefore, we can calculate the change in gravity that will be caused by any hypothetical behavior of injected fluid, and thus determine whether a given behavior can be detected with gravimetric techniques. We have also studied the possibility of using a borehole gravimeter in a geothermal environment and can, therefore, investigate the feasibility of borehole gravity not only by calculational studies but also by planning a field operation.

\section{Self-Potential Method}

Corwin and Hoover (1979) have summarized the use of self-potential measurements to delineate geothermal resources. They indicate that two mechanisms may cause observable electric potential anomalies over inhomogenous material: large temperature gradients and flowing fluid. We propose to evaluate whether signals produced by the latter mechanism (called streaming potentials) can be used to help monitor the location of injected brine. Corwin and Hoover describe instances where streaming potentials of $30-50 \mathrm{mV}$ were detected due to a leaking reservoir or pumping of shallow ground water from a well.

We will evaluate the possibility of using these potentials to map the flow around deep brine injection wells. Our approach will be as follows. First, analytical models of SP anomalies resulting from spherical flow will be 
calculated to determine the possible magnitude of anomalies and to evaluate whether lack of detailed knowledge of the electrokinetic coupling coefficients in situ will make it impossible to determine the flow from the field. If these tests indicate $S P$ is a promising diagnostic, we will evaluate possible surface and downhole measurement arrays and examine SP data from several geothermal areas to develop a possible field experiment. 
APPENDIX B - LLNL PARTICIPANTS AND OUTSIDE CONTACTS

Most of the work will be performed by staff scientists at LLNL. Major contributors to the program will include:

Lee Younker - Geothermal System Characterization

Jon Hanson - Geothermal Systems - Reservoir Modeling

Paul Kasameyer - Reservoir Modeling and Electrical Methods

Edna Didwal1 - Electrical Methods and Geotomography

Al Smith - Microseismicity and Acoustic Signal Transmission

W. Murray - Hydrology and Environmental Regulation

J. Hearst - Gravity Methods and Well Logging

D. Helm - Hydrology and Elevation Changes

B. Daily - Electrical Methods and Geotomography

N. Crow - Environnental Regulations and Geothermal Systems

In adaition to the 1 ab personnel, the program will benefit from outside contacts with individuals and related programs. These contacts will include:

1. Paul Susca - Energy Resources Company.

They are working on a related project for the E.P.A. in Cincinnati. Their reservoir data base on Western KGRA's and groundwater impact analysis for these sites will be of use to our evaluation of potential field sites.

2. Roy Mink: D.O.E. Raft River Their work on the characterization of a complex fracture-dominated system and their evaluation of injection well monitoring approaches will interface directly with our project. 
3. Doug Stockton - California Division of Oil and Gas This office will supply us with present California regulations that apply to geothermal brine injection programs.

4. Academic and Industrial Experts

We have made preliminary contacts with several experts outside LLNL familiar with technical options available for monitoring.

5. Industrial Contacts We have made preliminary contact with industries active in geothermal development. After the initial evaluation of approaches, we plan to contact these people and request input and review. 


\section{APPENDIX C - SCHEDULE AND MILESTONES}

The milestone chart is basically consistent with the chart from the WPAS with the following exceptions.

1. Technical assessment phase has been expanded to include measurement strategies and instrumentation needs. As a result, final document will be completed at the end of FY81.

2. Analysis of monitoring requirements and environmental regulations has been added as a result of request.

3. Analysis of field sites has been moved to the end of the year. This is so we can benefit from the results of the study by Energy Resources, and so we can have a preliminary idea of the feasibility of remote monitoring prior to contacting operators and developers. 
MILESTONE SCHEDULE

$\underline{\text { Tasks }}$

Technical

Assessment

of Monitoring

Approaches

Analysis of

Environmental

Regulations and

Monitoring

Requirements for

Injection Wells

Evaluation of

Possible Sites

for a Field

March April May June July August September October November December

Experiment

Field Experiment

Design

(System Modeling

and Experimental

Design)

a Technical Evaluation of Alternative Monitoring Approaches

b Assessment of Environmental Regulations and Monitoring Requirements for Geothermal Injection Wells

c List of Priority Sites for Field Experiment

d Final Recommendations on whether a Field Experiment Would be Useful

- Final Documentation 